\title{
Carbon-Coupling Metallic Cobalt as Trifunctional Catalysis for Oxygen Reduction/Evolution and Hydrogen Evolution
}

\author{
Zihao Zhou, Kangdi Lin, Chenting Peng, Hongyun Huang, Yanli Wu, and Ming Sun* \\ Key Laboratory of Clean Chemistry Technology of Guangdong Regular Higher Education Institutions, \\ Guangdong Provincial Key Laboratory of Plant Resources Biorefinery, School of Chemical Engineering \\ and Light Industry, Guangdong University of Technology, Guangzhou 510006 China
}

Email: sunmgz@gdut.edu.cn (M. S.)

\begin{abstract}
The next-generation energy storage focuses on sustainability and renewability, facilitating the process of metal-air batteries and fuel cells. Nevertheless, their performances are suffering from the tardy development of the elaborate design and large-scale synthesis strategy of cost-efficient electrocatalysts. In this work, a convenient strategy for facile synthesizing electroactive material is proposed. As a result, a trifunctional $\mathrm{Co} / \mathrm{C}$ catalyst is fabricated via a convenient calcination process, utilizing the pyrolysis of cobalt acetate and melamine. The prepared $\mathrm{Co} / \mathrm{C}$ sample delivers a positive half-wave potential of $0.75 \mathrm{~V}$ in oxygen reduction reaction (ORR). Furthermore, the low overpotentials at $10 \mathrm{~mA} \mathrm{~cm}^{-2}$ are shown in alkaline conditions for oxygen evolution reaction (OER, $388 \mathrm{mV}$ ) and hydrogen evolution reaction (HER, $202 \mathrm{mV}$ ). The improved activity is mainly due to the interaction between $\mathrm{Co}$ and the in situ formed carbon carrier. The promising trifunctional activities endow the $\mathrm{Co} / \mathrm{C}$ sample with a bright prospect in metal-air batteries and overall water splitting.
\end{abstract}

Keywords trifunctional catalyst, oxygen reduction, oxygen evolution, hydrogen evolution

\section{Introduction}

Renewable energy storage devices represented by metal-air batteries and fuel cells are obtaining much attention owing to the carbon neutrality policy and the transformation of energy structure. To some extent, the discharging and charging ability of these devices successively hinging on the oxygen reduction (ORR) and oxygen evolution (OER) properties of the electrocatalyst. In other words, these devices severely suffer from the sluggish kinetics and low energy conversion efficiency of ORR and OER. ${ }^{[1]}$ Therefore, the development of promising bifunctional ORR/OER catalysts is crucial to the commercialization of the devices. Unfortunately, the current commercial catalysts for fuel cells and metal-air batteries are mainly Pt-, Ir- and Ru-based precious metals materials, which are limited by their scarcity, high price, poor toxicity resistance, and unsatisfactory stability. ${ }^{[2,3]}$ As a result, it is imperative and urgent to explore earth-abundant, cost-effective, and stable non-noble metal electrocatalysts, especially bifunctional ORR/OER catalysts.

So far, carbon-supported metal materials, such as carbon-coupling metallic cobalt, are eye-catching due to their good electronic conductivity, favorable chemical and mechanical stability, and abundant nano-/micro-structures. ${ }^{[4]}$ Considering the chemical substitution reaction of the active metal atoms in catalysts and the $\mathrm{H}^{+}$ions in acidic electrolytes, alkaline electrolytes are more suitable for such catalysts to provide a suitable working environment. ${ }^{[5]}$ In recent years, carbon-supported transition metal oxides/sulfides/hydroxides are proved to be good ORR/OER/HER catalysts. ${ }^{[6-9]}$ For example, Qiu and co-authors developed a flash Joule heating method for synthesizing $\mathrm{Ag} / \mathrm{Co} / \mathrm{C}$ hybrid ORR catalyst. $^{[5]}$ Rasaki's group reported Pt-comparable carbon-supported cobalt $\left(\mathrm{C} @ \mathrm{CoC}_{x}\right)$ ORR catalyst. ${ }^{[10]}$ Furthermore, Chen's group designed a complex $\mathrm{CoC}_{x}$-based compound with CoFe phosphide and carbon carrier, denoted as
$\mathrm{CoC}_{x} /\left(\mathrm{Co}_{0.55} \mathrm{Fe}_{1.945}\right)_{2} \mathrm{P} @ \mathrm{C}$. The compound displayed excellent ORR and OER activity in $0.1 \mathrm{M} \mathrm{KOH}$ electrolyte and even in rechargeable zinc-air batteries. ${ }^{[11]}$ Zhang et al. synthesized a ternary Fe/Co/WC@NC ORR catalyst via a one-pot strategy. Interestingly, the methanol tolerance ability of Fe/Co/WC@NC endows prospects in fuel cells. ${ }^{[12]}$ Unfortunately, the complex elementary composition and hierarchical structure increase the cost and difficulty in manufacturing and thus hinder the large-scale preparation and application of these catalysts. Therefore, it is promising to develop a convenient and affordable strategy to produce carbon-coupling metallic cobalt multifunctional electrocatalyst.

Herein, we propose a convenient strategy for large-scale synthesizing Co/C for ORR, OER, and HER catalysis. Briefly, this strategy bases on the pyrolytic reaction of melamine and the carbonation reaction of $\mathrm{Co}^{2+}$ in $\mathrm{Co}(\mathrm{Ac})_{2} \cdot 4 \mathrm{H}_{2} \mathrm{O}$ precursor. Further, $\mathrm{Co}^{2+}$ is partially reduced to metallic $\mathrm{Co}$ by the reductive carbon species in $\mathrm{Co}(\mathrm{Ac})_{2} \cdot 4 \mathrm{H}_{2} \mathrm{O}$ and/or melamine. In the presence of melamine, the produced metallic cobalt nanoparticles couple with carbon and uniformly disperse, and thus the product $\mathrm{Co} / \mathrm{C}$ sample remains nano-scale morphology. In the absence of melamine, the produced metallic cobalt nanoparticles tend to agglomerate and form larger microparticles, denoted as the Co sample. For electrochemical properties, the $\mathrm{Co} / \mathrm{C}$ sample displays a Pt-comparable half-wave potential of $0.75 \mathrm{~V}$ versus RHE for the ORR, and low overpotentials at $10 \mathrm{~mA} \mathrm{~cm}^{-2}\left(\eta_{10}\right)$ of 388 and $202 \mathrm{mV}$ respectively for OER and HER, which confirms it a trifunctional electrocatalyst, and endows it a bright prospect in metal-air batteries and fuel cells. Subsequently, we investigate the electrocatalytic properties of Co nanoparticles. As a result, the Co sample exhibits moderate activity of ORR $\left(E_{1 / 2}=0.69 \mathrm{~V}\right)$, and high overpotentials of OER $\left(\eta_{10}=431 \mathrm{mV}\right)$ and $\operatorname{HER}\left(\eta_{10}=\right.$ $394 \mathrm{mV}$ ). With the professional characteristics of XRD, SEM, and XPS, we study the detailed structure of $\mathrm{Co} / \mathrm{C}$ and $\mathrm{Co}$, and 
illuminate the relationship between structure and electrochemical performance.

\section{Experimental}

\section{Synthesis of $\mathrm{Co} / \mathrm{C}$}

The $\mathrm{Co} / \mathrm{C}$ was synthesized via a pyrolysis reaction. To be specific, $4.0 \mathrm{~g} \mathrm{Co}(\mathrm{Ac})_{2} \cdot 4 \mathrm{H}_{2} \mathrm{O}$ and $2.0 \mathrm{~g}$ melamine were added into a glass dish with ethanol, followed by ultrasonic dispersion to form a uniform suspension. The obtained suspension was dried at $80{ }^{\circ} \mathrm{C}$ overnight and then pulverized to obtain uniform violet powder as the precursor. The precursor was transferred to a corundum porcelain boat and placed in a tube furnace, subsequently heated at $550{ }^{\circ} \mathrm{C}$ for $2 \mathrm{~h}$ under $\mathrm{N}_{2}$ with a heating rate of $5{ }^{\circ} \mathrm{C} \mathrm{min}{ }^{-1}$. The obtained black powder was $\mathrm{Co} / \mathrm{C}$ nanoparticles.

\section{Synthesis of metallic Co}

The manufacturing method of the Co sample was similar to the $\mathrm{Co} / \mathrm{C}$ sample except for that only $\mathrm{Co}(\mathrm{Ac})_{2} \cdot 4 \mathrm{H}_{2} \mathrm{O}$ was used as the precursor.

\section{Materials characterization}

The crystal structure and surface structure of three samples were successively studied by powder X-ray diffraction (XRD, PANalytical, X'Pert3, Cu target), scanning electron microscope (SEM, Hitachi, SU8220), Raman spectra (LabRAM HR, $\lambda=633$ $\mathrm{nm}$ ), transmission electron microscopy (TEM, Thermo, Talos F200S), and X-ray photoelectron diffraction (XPS, Escalab $250 \mathrm{Xi}$, Al target). Moreover, the pyrolysis processes were analyzed by thermogravimetric and differential thermal analysis (NETZSCH, STA409PC, TGA-DTA) under the $\mathrm{N}_{2}$ atmosphere with a rate of $5{ }^{\circ} \mathrm{C} \mathrm{min}$.

\section{Electrocatalytic measurements}

The OER, HER, and ORR performances were examined by cyclic voltammetry $(\mathrm{CV})$ curves and linear sweep voltammetry (LSV), finished in a $\mathrm{CHI} 760 \mathrm{E}$ electrochemical workstation. Unless otherwise noted, all electrochemical measurements mentioned were performed on a three-electrode system assembling with a working electrode, a graphite rod counter electrode, and an $\mathrm{Ag} / \mathrm{AgCl}$ reference electrode containing a 3.5 $\mathrm{M} \mathrm{KCl}$ internal reference solution. Unless otherwise specified, the potentials mentioned in this work are represented by the potentials versus $\mathrm{RHE}$.

The OER and HER performances were measured in $\mathrm{N}_{2}$-saturated $1 \mathrm{M} \mathrm{KOH}$ solution, which working electrode was a carbon fiber paper (CFP) with surface coated catalyst with a mass loading of $0.86 \pm 0.05 \mathrm{mg} \mathrm{cm}^{-2}$. The catalyst ink was dripped onto the surface of CFP and then dried at $60^{\circ} \mathrm{C}$.

The ORR performance and electrochemical surface area (ECSA) were measured in $\mathrm{O}_{2}$-saturated $0.1 \mathrm{M} \mathrm{KOH}$ solution, which working electrode was respectively a rotating ring disk electrode (RRDE) and a rotating disk electrode (RDE) loading with catalyst on the ring with a mass loading of $0.135 \pm 0.005$ $\mathrm{mg} \mathrm{cm}{ }^{-2}$. Especially, LSV curves of ORR were collected in a four-electrode system using an RRDE as a working electrode.

\section{The rechargeable zinc-air batteries measurements}

The rechargeable zinc-air battery was assembled by a polished zinc plate, a stainless-steel mesh coated with a catalyst, a membrane separator, and a set of metal-air battery molds (OMS-T1). The $6 \mathrm{M} \mathrm{KOH}$ electrolyte is with an additive of $0.2 \mathrm{M} \mathrm{Zn}(\mathrm{Ac})_{2}$. The measurements of zinc-air batteries were conducted on a LAND CT3001A $1 \mathrm{U}$ system and a CHI 760E electrochemical workstation.

\section{Results and Discussion}

\section{Structural and morphological properties}

The crystal phases of the samples are detected by XRD (Figure 1). Briefly, the XRD pattern of both $\mathrm{Co}$ and $\mathrm{Co} / \mathrm{C}$ samples show diffraction peaks at around $44.4^{\circ}, 51.7^{\circ}$, and $75.9^{\circ}$, which matches well with the (111), (200), and (220) facets of cubic Fm-3m structure of metallic Co (PDF\# 15-0806). Moreover, no impure diffraction signal could be detected, indicating the successful formation of metallic Co via calcination. In other words, $\mathrm{Co}(\mathrm{Ac})_{2} \cdot 4 \mathrm{H}_{2} \mathrm{O}$ dehydrates and decomposes into well-crystalline metallic $\mathrm{Co}$ nanoparticles with or without melamine. Interestingly, the XRD pattern of the $\mathrm{Co} / \mathrm{C}$ sample displays a weaker intensity of diffraction peaks than that of the Co sample, suggesting that the partial lattice distortion is caused by the coupling of metallic cobalt and the carbon derived from melamine. No obvious signals indexing to carbon species are detected, indicating that the $\mathrm{C}$ atoms are highly dispersed in the cobalt phase instead of producing $g-C_{3} N_{4}{ }^{\left[{ }^{[1,14]}\right.}$

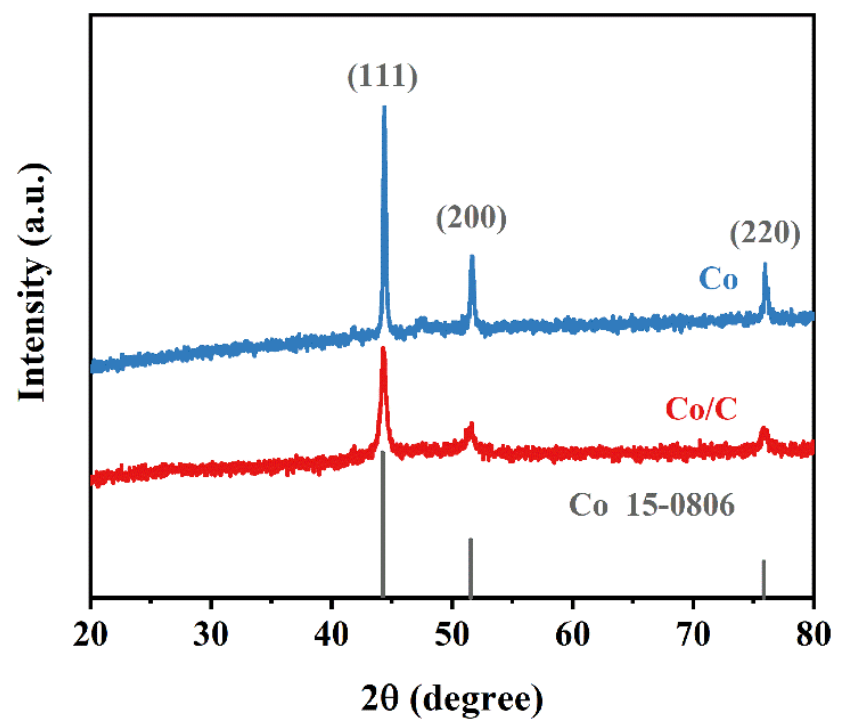

Figure 1 XRD patterns of $\mathrm{Co} / \mathrm{C}$ and Co sample.

Raman spectra roughly offer surface information of $\mathrm{Co} / \mathrm{C}$ and Co samples. Figure 2 shows Raman scattering modes assign to the $\mathrm{F}_{2 \mathrm{~g}}, \mathrm{E}_{\mathrm{g}}$, and $\mathrm{A}_{1 \mathrm{~g}}$ vibration peaks of $\mathrm{Co}_{3} \mathrm{O}_{4}$, the peaks in which at $\sim 190$ and $670 \mathrm{~cm}^{-1}$ are indexed to the stretching modes of $\mathrm{Co}-\mathrm{O}$ bonds in octahedron and tetrahedron, respectively. ${ }^{[15]}$ The detection of Co-O implies the surface oxidation of metallic $\mathrm{Co}$, possibly due to the oxidation of atmosphere, and the heat effect of the Raman testing process and consistent with the active reducibility of $\mathrm{Co}$. Additionally, the signals at $\sim 1350$ for the $D$ band and $\sim 1580 \mathrm{~cm}^{-1}$ for the $\mathrm{G}$ band are the typical Raman scattering of carbon. ${ }^{[16]}$ Unfortunately, no distinct peaks corresponding to the $\mathrm{C}-\mathrm{C}$ bonds are detected, probably due to the strong signal of $\mathrm{Co}$, and the weak crystallinity of carbon in $\mathrm{Co} / \mathrm{C}$ and Co samples.

The differences in morphology and elementary composition of the two samples were observed by SEM. Figure 3a demonstrates the nanosphere morphology of the $\mathrm{Co} / \mathrm{C}$ sample with a diameter in the range of $20-80 \mathrm{~nm}$. On the contrary, Figure $3 \mathrm{~b}$ shows the bulk morphology on the micron scale of the Co sample, implying the agglomeration of products during pyrolysis in the absence of melamine. The carbon nanoparticles derived from the pyrolysis of melamine might promote the dispersion of Co species. 

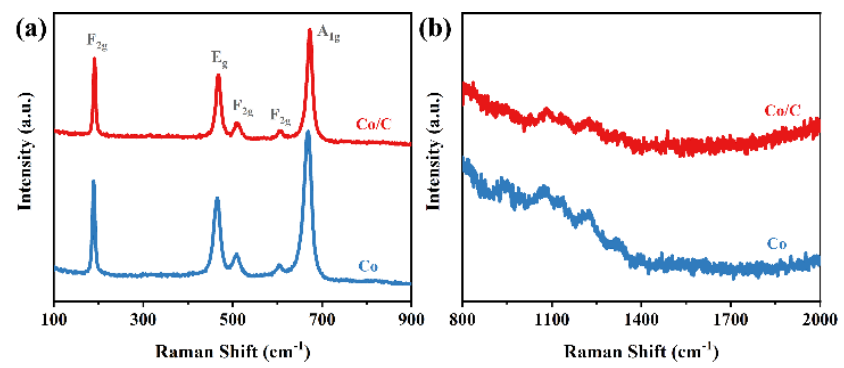

Figure 2 Raman spectra of $\mathrm{Co} / \mathrm{C}$ and Co sample.

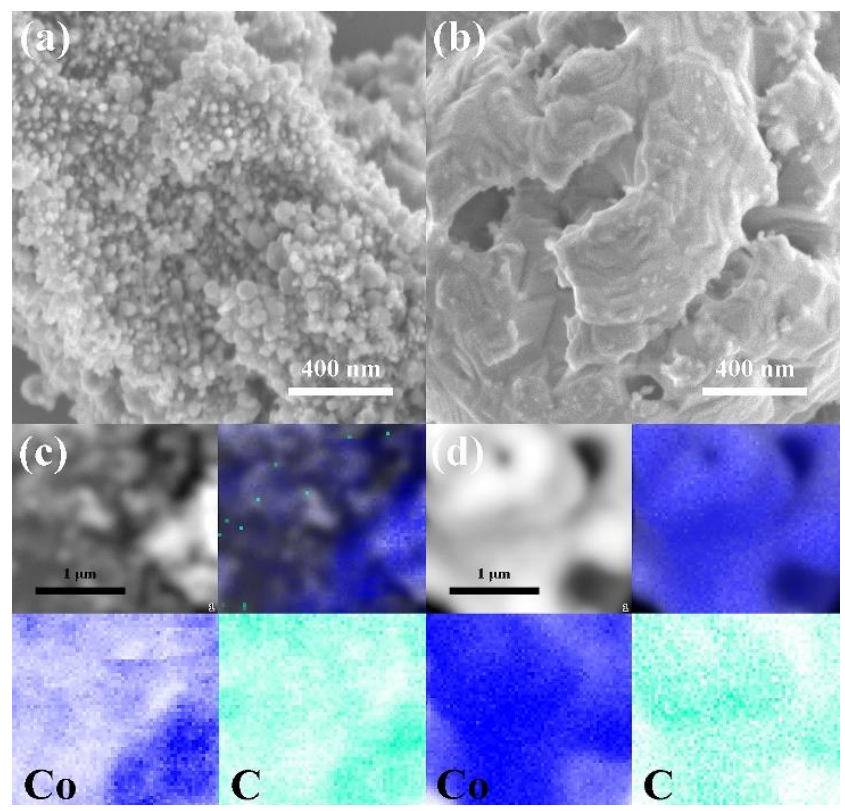

Figure 3 SEM images and element mapping of $(a, c) ~ C o / C$ and (b, d) Co sample.

Table 1 Quantitative analysis of element via EDS

\begin{tabular}{ccccc}
\hline Samples & Co (atom\%) & $\mathrm{C}$ (atom\%) & Co (w\%) & C (w\%) \\
\hline Co/C & 68.00 & 32.00 & 91.25 & 8.75 \\
Co & 99.15 & 0.88 & 99.82 & 0.18 \\
\hline
\end{tabular}

The difference in elementary composition is certified by energy disperse spectroscopy (EDS) as shown in Figures 3c, $3 d$, and Table 1. Dominant Co atoms (99.12 atom\%) and negligible $\mathrm{C}$ atoms (0.88 atom\%) are detected. The probable resources of $C$ atoms in the Co sample include that the pyrolysis of residual acetate, the carbon pollutants on silicon wafers, and the carbon in conductive adhesives. On the contrary, abundant C atoms (32.00 atom\%) are present in the $\mathrm{Co} / \mathrm{C}$ sample owing to the pyrolysis of melamine. The atomic ratio of $C o$ and $C$ in the $C o / C$ sample reaches $2.1: 1$. Herein, the $\mathrm{C}$ atoms promote the dispersion of $\mathrm{Co}$ atoms, which explains the morphological advantage of the $\mathrm{Co} / \mathrm{C}$ sample

The morphology and elementary distribution of the two samples were further tested via TEM. In terms of morphology, the TEM patterns in Figures $4 \mathrm{a}$ and $4 \mathrm{~b}$ demonstrate that the nanoparticles in the $\mathrm{Co} / \mathrm{C}$ sample are dispersed, while the particles in the Co sample are seriously agglomerated. Furthermore, the high-resolution image in Figures $4 \mathrm{c}$ and $4 \mathrm{~d}$ displays a lattice fringe with a distance of $0.247 \mathrm{~nm}$ indexed to the (111) facet of metallic Co (PDF\# 15-0806). In the Co sample, the crystal area is larger and the crystal fringe is clearer, indicating its higher crystallinity than the $\mathrm{Co} / \mathrm{C}$ sample, which is in good agreement with XRD results. Compared with the

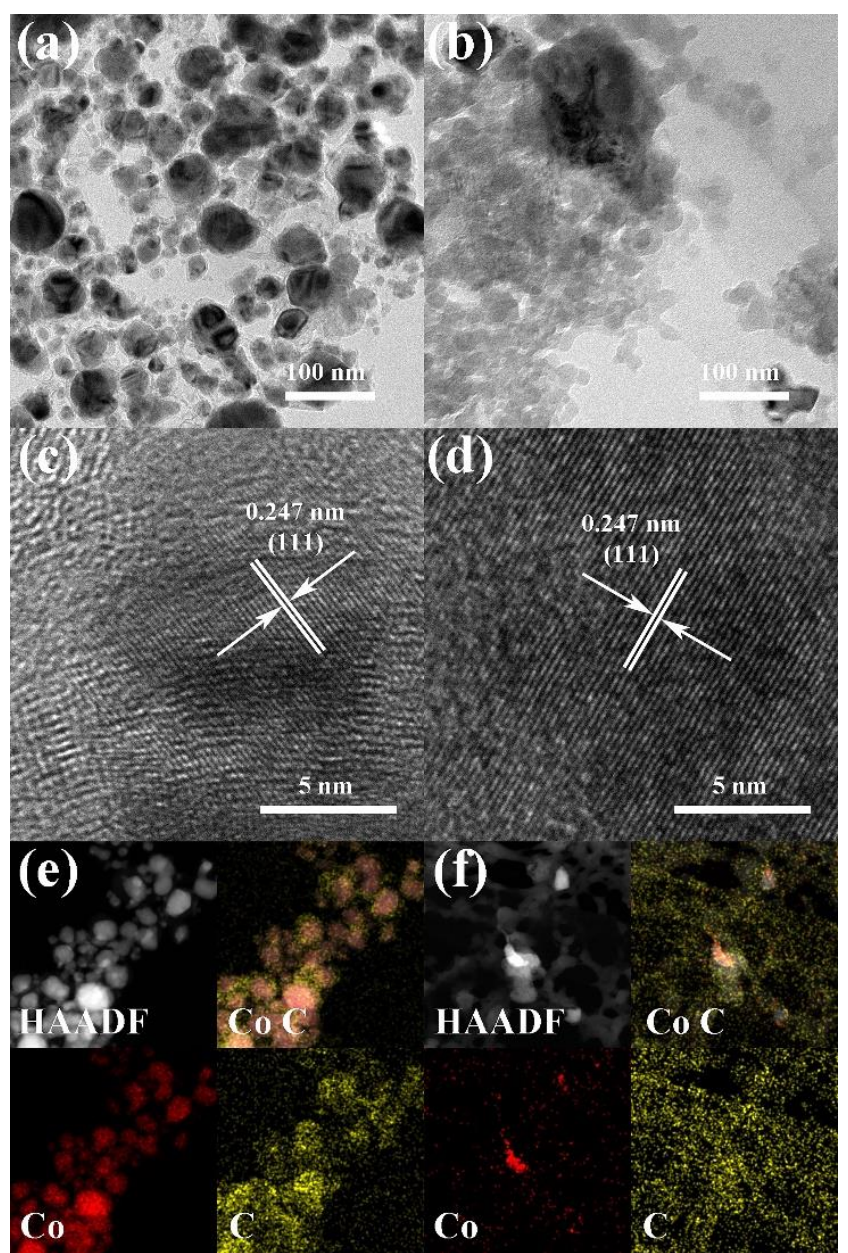

Figure 4 TEM images and elementary mapping of (a, c, e) $\mathrm{Co} / \mathrm{C}$ and (b, d, f) Co samples.

element distribution in the Co sample, the Co atoms are evenly dispersed between the $\mathrm{C}$ atoms in the $\mathrm{Co} / \mathrm{C}$ nanoparticles. It can be concluded that the addition of melamine can inhibit the growth of particles and thus control the particle size.

The XPS were carried out to analyze the surface natures of two samples. The binding energy of the $\mathrm{C}-\mathrm{C}$ bond $(284.8 \mathrm{eV})$ in the $C$ 1s region was used as the reference standard for calibrating Co $2 p$ and $O$ 1s regions. According to Figure $5 a$, Co atoms in the $\mathrm{Co} / \mathrm{C}$ sample display five deconvolution peaks located at around 777.8, 779.6, 781.1, 784.8, and 786.4 eV, which could be separately indexed to metallic $\mathrm{Co}^{0}, \mathrm{Co}^{3+}$ ions, $\mathrm{Co}^{2+}$ ions, and the satellite signal reflected the spin-orbit splitting of $\mathrm{Co}^{2+/ 3+} \cdot{ }^{117,18]}$ Due to the active chemical properties of metallic $\mathrm{Co}^{0}$, the $\mathrm{Co}^{2+}$ and $\mathrm{Co}^{3+}$ ions are probably generated via a spontaneous oxidation reaction of metallic $\mathrm{Co}^{0}$ by the oxygen from the air, which agrees with the Raman test, and such phenomenon has been reported. ${ }^{[19,20]}$ Interestingly, the peak on behalf of metallic $\mathrm{Co}^{0}$ in Figure $5 \mathrm{~b}$ is more intense in the Co sample rather than that in the $\mathrm{Co} / \mathrm{C}$ sample, indicating that cobalt atoms tend to be in elemental form in absence of carbon particles. Therefore, it could be inferred that the carbon particles derived from melamine could: accelerate the oxidation of metallic cobalt atoms and create more $\mathrm{Co}^{2+/ 3+}$ species, which optimize the electronic structure of the $\mathrm{Co} / \mathrm{C}$ sample. For the $\mathrm{O}$ $1 \mathrm{~s}$ region of $\mathrm{Co} / \mathrm{C}$ sample, Figure $5 \mathrm{c}$, three peaks appeared at around 529.4, 531.6, and 533.5 eV indicate the existence of lattice oxygen, surface chemisorbed oxygen (hydroxyl), and adhering water, ${ }^{[21]}$ which evidence the oxidation of metallic $\mathrm{Co}^{0}$. The $O 1$ s spectrum of the Co sample in Figure $5 d$ shows deconvolution peaks similar to that of the $\mathrm{Co} / \mathrm{C}$ sample. 

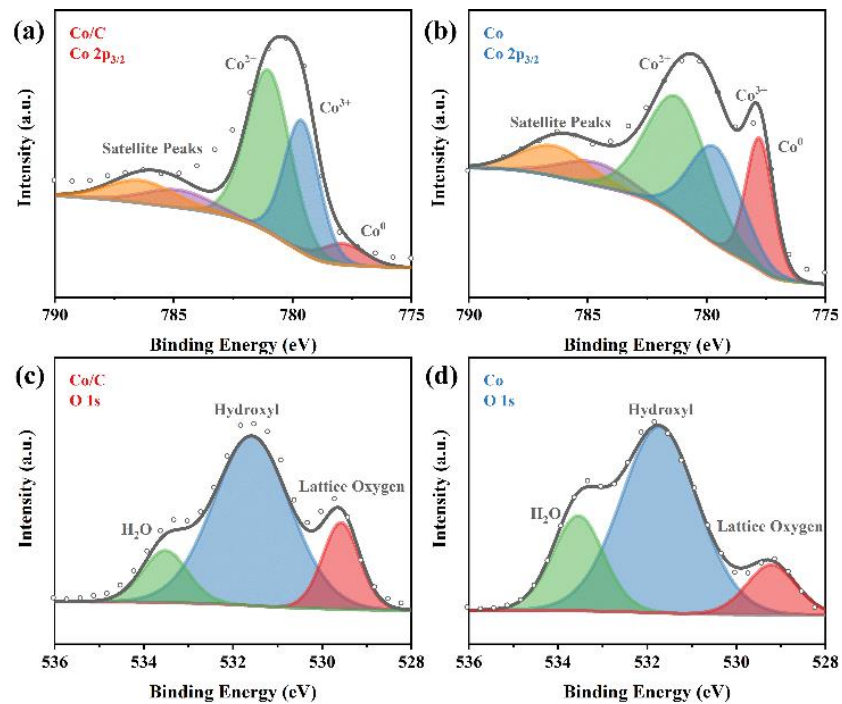

Figure 5 XPS spectra of Co $2 p$ and $O$ 1s spectra of $(a, c)$ $\mathrm{Co} / \mathrm{C}$ and (b, d) Co sample.

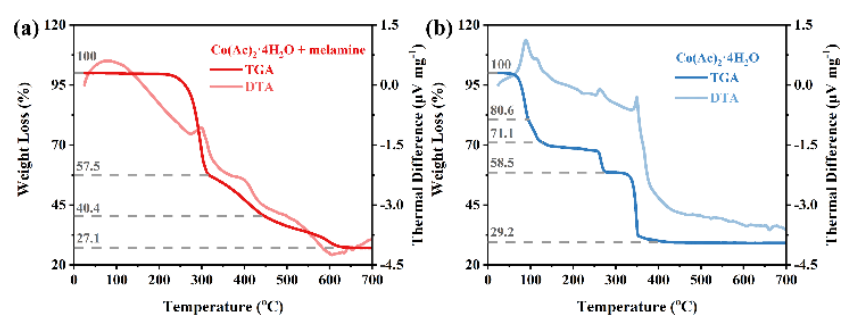

Figure 6 TGA-DTA curves of the pyrolysis processes of (a) the mixture of melamine and $\mathrm{Co}(\mathrm{Ac})_{2} \cdot 4 \mathrm{H}_{2} \mathrm{O}$ and $(b)$ the pure $\mathrm{Co}(\mathrm{Ac})_{2} \cdot 4 \mathrm{H}_{2} \mathrm{O}$.

The pyrolysis processes of $\mathrm{Co} / \mathrm{C}$ and Co samples were analyzed via TGA and DTA. As can be seen in Figure $6 \mathrm{~b}$, a typical TGA curve of $\mathrm{Co}(\mathrm{Ac})_{2} \cdot 4 \mathrm{H}_{2} \mathrm{O}$ is collected. The rapid weight losses of $28.9 \%, 41.5 \%$, and $70.8 \%$ successively reflect the processes of the melting of $\mathrm{Co}(\mathrm{Ac})_{2} \cdot 4 \mathrm{H}_{2} \mathrm{O}$ and the dehydration of water molecules, the generation of basic cobalt acetate, and the further pyrolysis to form dominant metallic Co and minor carbon residue. ${ }^{[22]}$ However, in the presence of melamine, the TGA curve changed significantly, as shown in Figure $6 \mathrm{a}$, probably because melamine affected the dehydration of $\mathrm{Co}(\mathrm{Ac})_{2} \cdot 4 \mathrm{H}_{2} \mathrm{O}$ and the formation of basic cobalt acetate. ${ }^{[23]}$ Briefly, the residual mass of the mixture of $\mathrm{Co}(\mathrm{Ac})_{2} \cdot 4 \mathrm{H}_{2} \mathrm{O}$ and melamine is $27.1 \%$ after TGA, similar to that of $29.2 \%$ of $\mathrm{Co}(\mathrm{Ac})_{2} \cdot 4 \mathrm{H}_{2} \mathrm{O}$.

\section{Electrocatalytic performances}

To investigate the ORR performances of two samples, CV was firstly carried out. Figure $7 \mathrm{a}$ shows the CV curves separately collected in $0.1 \mathrm{M} \mathrm{KOH} \mathrm{O}_{2}$-saturated solution. Especially, the CV curve of the Co sample displays an identifiable oxygen reduction peak is detected at around $0.68 \mathrm{~V}$ (versus $\mathrm{RHE}$ ) in $\mathrm{O}_{2}$-saturated solution. For the $\mathrm{Co} / \mathrm{C}$ sample, the reduction peak shifts to a positive potential, which is $69 \mathrm{mV}$ higher than the Co sample. To further evaluate the ORR properties, LSV curves were measured and illustrated in Figure 7b. In terms of activity, the $\mathrm{Co} / \mathrm{C}$ sample displays a positive half-wave potential of $0.75 \mathrm{~V}$ at $2.49 \mathrm{~mA} \mathrm{~cm}^{-2}$ surpassing the Co sample $\left(0.69 \mathrm{~V}\right.$ at $\left.1.99 \mathrm{~mA} \mathrm{~cm}^{-2}\right)$, manifesting that the $\mathrm{Co} / \mathrm{C}$ sample is more active than the Co sample. For reaction kinetics, the $\mathrm{Co} / \mathrm{C}$ sample exhibits a larger diffusion-limited current density ( $(\dot{L})$ of $4.97 \mathrm{~mA} \mathrm{~cm}{ }^{-2}$, suggesting its rapid reaction kinetics. On the contrary, the $\dot{j} L$ of the Co sample is relatively
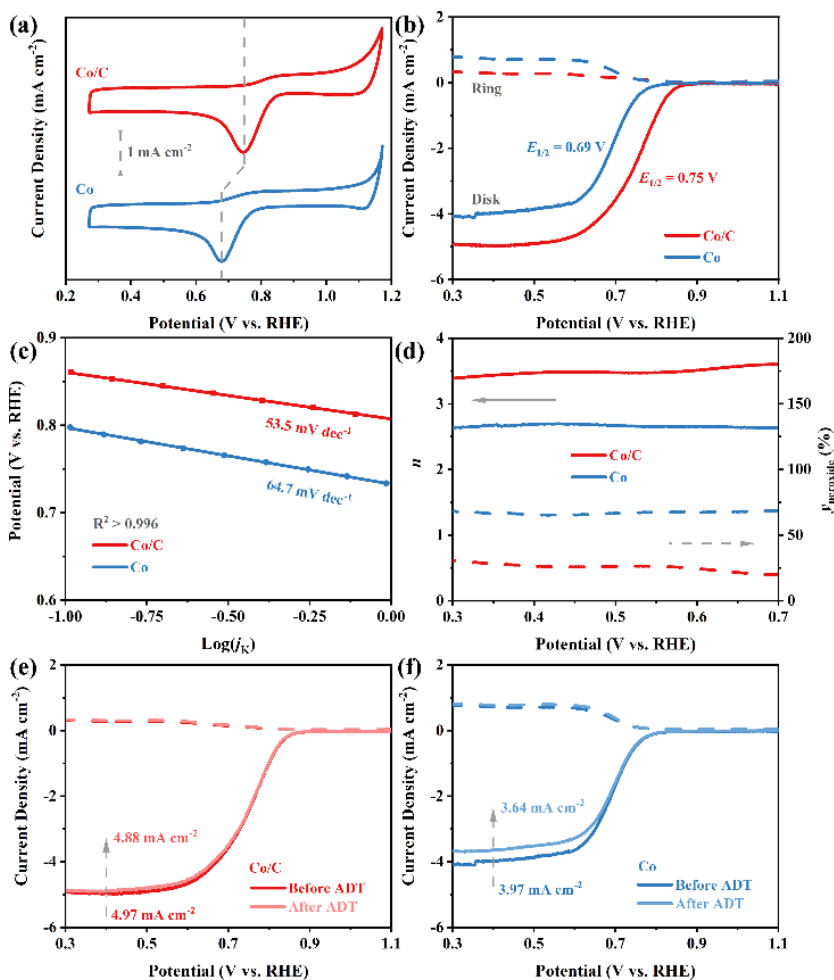

Figure 7 ORR performance of the two samples: (a) CV curves and (b) LSV curves; (c) Tafel plots; (d) the number of transferred electrons $(n)$ and the yield of peroxide ( $\left.y_{\text {peroxide }}\right)$; and (e, f) LSV curves before and after the accelerated aging tests.

moderate $(3.97 \mathrm{~mA} \mathrm{~cm}$ ), hinting at its sluggish kinetic response. The Tafel plots were drawn in Figure $7 \mathrm{c}$ for a rough understanding of the reaction mechanism. The $\mathrm{Co} / \mathrm{C}$ sample possesses a promising Tafel slope of $53.5 \mathrm{mV} \mathrm{dec}^{-1}$, attributed to the Temkin-type oxygen adsorption mode. ${ }^{[24]}$ In contrast, the Tafel slope of the Co sample exhibits a moderate Tafel slope of $64.7 \mathrm{mV} \mathrm{dec}^{-1}$, suggesting its relatively sluggish reaction kinetics.

For a deeper sight into the reaction mechanism, the number of transferred electrons $(n)$ and the yield of peroxide ( $y_{\text {peroxide }}$ ) were calculated based on the relative relationship between the ring current and the disk current, illustrated in Figure $7 \mathrm{~d}$. Compared with the Co sample, the reaction mechanism of the $\mathrm{Co} / \mathrm{C}$ sample is closer to the four-electron transfer pathway than that of the Co sample. To be specific, the $\mathrm{Co} / \mathrm{C}$ sample exhibits an average electron transfer number $(n)$ of 3.49 per oxygen molecule, and an average yield of peroxide ( $\left.y_{\text {peroxide }}\right)$ of $25.5 \%$ in the potential range of 0.3 to $0.7 \mathrm{~V}$. In stark contrast, the $n$ of Co sample is 2.66 per oxygen molecule, signifying the sluggish two-electron transfer pathway occurred. As a consequence, the $y_{\text {peroxide }}$ of the Co sample is approached $75.6 \%$, which is much higher than that of the $\mathrm{Co} / \mathrm{C}$ sample.

Stability was evaluated by the accelerated aging test (ADT). ADT was conducted in the potential range of 0.57 to $0.77 \mathrm{~V}$ for 1000 cycling with a scan rate of $100 \mathrm{mV} \mathrm{s}^{-1}$. According to Figures $7 \mathrm{e}$ and $7 \mathrm{f}$, the $\mathrm{Co} / \mathrm{C}$ sample demonstrates an inappreciable $E_{1 / 2}$ decay of a few millivolts and a mildly decrease of $j L$ from 4.97 to $4.88 \mathrm{~mA} \mathrm{~cm}^{-2}$. However, the $j L$ of the Co sample is sharply declined from 3.97 to $3.64 \mathrm{~mA} \mathrm{~cm}^{-2}$ during ADT, suggesting its poor electrochemical stability.

OER and HER were measured to further explore the electrochemical properties of the $\mathrm{Co} / \mathrm{C}$ sample, which results were drawn in Figure 8. For OER, Co/C sample and Co sample display comparable activity in $\mathrm{N}_{2}$-saturated $1 \mathrm{M} \mathrm{KOH}$ solution. Briefly, the overpotential at $10 \mathrm{~mA} \mathrm{~cm}^{-2}\left(\eta_{10}\right)$ of the $\mathrm{Co} / \mathrm{C}$ sample 

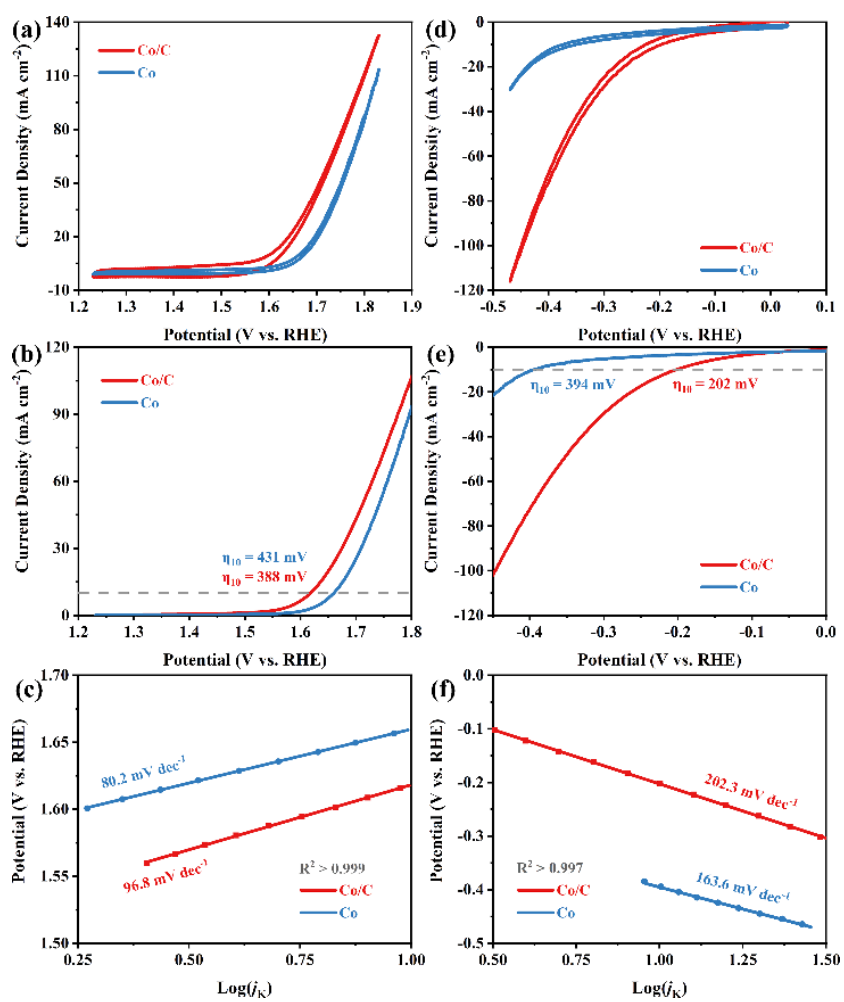

Figure 8 CV curves, LSV curves, and Tafel plots of $(a-c)$ OER and (d-f) HER.

is $388 \mathrm{mV}$, which is $43 \mathrm{mV}$ lower than that of the Co sample, indicating the better OER activity of the $\mathrm{Co} / \mathrm{C}$ sample. Moreover, the Co/C sample affords a smaller Tafel slope of $80.2 \mathrm{mV} \mathrm{dec}^{-1}$ than the Co sample $\left(96.8 \mathrm{mV} \mathrm{dec}^{-1}\right)$, confirming its rapid reaction kinetics. For HER, the current density of the $\mathrm{Co} / \mathrm{C}$ sample increases with the increase of overpotential. The coupling of carbon endows $\mathrm{Co} / \mathrm{C}$ sample an excellent HER activity with a low $\eta_{10}$ of $202 \mathrm{mV}$. Moreover, the Co/C sample possesses a large current density over $100 \mathrm{~mA} \mathrm{~cm}^{-2}$ at $-0.45 \mathrm{~V}$. However, the Co sample fails to reach a comparable current density, which is approached to one-fifth that of the $\mathrm{Co} / \mathrm{C}$ sample at $-0.45 \mathrm{~V}$.

Considering that the accessible surface area of catalysts is generally very different in $\mathrm{N}_{2}$-adsorption/desorption test and the electrochemical processes in the alkaline electrolyte. In this work, the electrochemically active surface area (ECSA) is used to determine the accessible surface area. ${ }^{[25]}$ In general, the larger the Cdl, the larger the ECSA. ${ }^{[26]}$ Therefore, the ECSA of two samples is assessed by $C_{\text {dll. }}$. Figures $9 a$ and $9 \mathrm{~b}$ show CV curves of two samples measured in a non-faradic range from 0.87 to $0.97 \mathrm{~V}$. Interestingly, the Co sample possesses a $C_{\mathrm{dl}}$ of $2.00 \mathrm{mF} \mathrm{cm}^{-2}$ twice as large as that of the $\mathrm{Co} / \mathrm{C}$ sample $(0.99$ $\mathrm{mF} \mathrm{cm}{ }^{-2}$ ), which reveals the higher specific activities of $\mathrm{Co} / \mathrm{C}$ sample probably derived from optimizing of the electron structure of cobalt by coupling with carbon.

Brief discussion. The $\mathrm{Co} / \mathrm{C}$ catalyst displayed a better activity than its counterpart, and this can be understood by the following reasons: 1 ) the $\mathrm{Co} / \mathrm{C}$ catalyst has a relatively smaller size and good dispersion, this could favor for the expose and application of active sites; 2 ) the $\mathrm{Co} / \mathrm{C}$ catalyst has relatively more carbon, and carbon play three key roles, one is for the dispersion of $\mathrm{Co}$, and the other is its electrochemical activity, as carbon is one of most reported catalysts for ORR/OER; moreover, the interaction between carbon and Co could also help for the improvement of the activity.
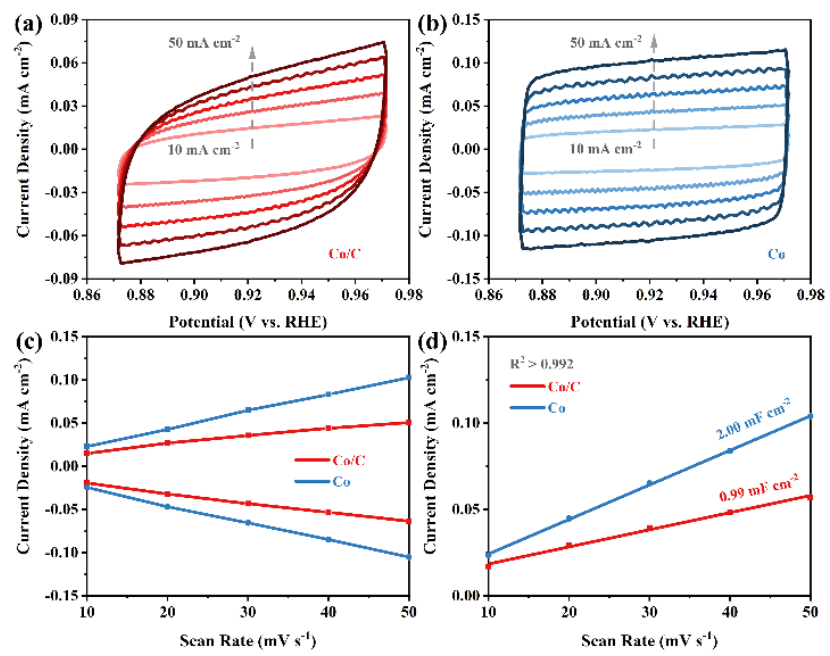

Figure $9(\mathrm{a}, \mathrm{b})$ The $\mathrm{CV}$ curves collected in $0.1 \mathrm{M} \mathrm{KOH}$ under $\mathrm{N}_{2}$ with scan rate ranging from 10 to $50 \mathrm{mV} \mathrm{s}^{-1}$, and (c, d) the plots of current density against scan rate.
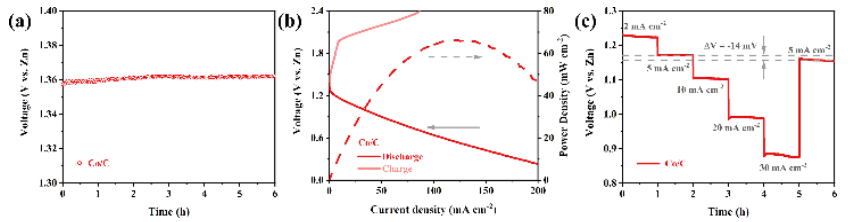

Figure 10 The rechargeable zinc-air battery performances of $\mathrm{Co} / \mathrm{C}$ sample: (a) open-circuit voltage $\left(V_{\text {oc }}\right)$, (b) polarization curve and power density, and (c) discharge curves under different current densities.

\subsection{The rechargeable zinc-air batteries performances}

In the respect of availability, measurements in the rechargeable zinc-air batteries were required for the $\mathrm{Co} / \mathrm{C}$ sample. Figure 10a shows that the rechargeable zinc-air battery with $\mathrm{Co} / \mathrm{C}$ demonstrates a horizontal $V_{\mathrm{oc}}$ of $\sim 1.36 \mathrm{~V}$ ( $v s$. $\mathrm{Zn}$ ) during the 6-hour open-circuit voltage test, which difference is about $0.29 \mathrm{~V}$ from the theoretical $V_{\text {oc }}(1.65 \mathrm{~V}$ vs. $\mathrm{Zn}) .{ }^{[27]}$ After 6 hours of standing, the $V_{\text {oc }}$ of the battery increased by $37 \mathrm{mV}$. The charging and discharging polarization curve of the battery was measured to deliver the information of power density. According to Figure 10b, the battery displays a promising peak power density of $66.0 \mathrm{~mW} \mathrm{~cm}$ at $124.5 \mathrm{~mA} \mathrm{~cm}^{-2}$. The battery was sequentially discharged at a series of current densities of 2 , $5,10,20,50,5 \mathrm{~mA} \mathrm{~cm}{ }^{-2}$ for $1 \mathrm{~h}$ each to estimate the discharging rate performance, which results is illustrated in Figure 10c. The output voltage in the second segment drops by only $14 \mathrm{mV}$ compared to that of the first segment of the discharging curve at $5 \mathrm{~mA} \mathrm{~cm}$, evidencing the extraordinary rate of performance of the $\mathrm{Co} / \mathrm{C}$ sample. Herein, the promising power density and stability of the $\mathrm{Co} / \mathrm{C}$ sample render strong proof of its practicability in the rechargeable zinc-air battery. Additionally, the good HER and OER properties could provide the $\mathrm{Co} / \mathrm{C}$ sample a bright prospect in overall water splitting, which does not further study in this work. The electrochemical performance of Co-based materials in recent reports is listed in supporting information (Table S1), which shows that the $\mathrm{Co} / \mathrm{C}$ sample is a promising trifunctional catalyst in the contemporary.

\section{Conclusions}

In summary, an efficient trifunctional $\mathrm{Co} / \mathrm{C}$ catalyst with moderate ORR, OER, and HER activity was successfully prepared. Briefly, the $\mathrm{Co} / \mathrm{C}$ sample displays promising ORR activity with the half-wave potential of $0.75 \mathrm{~V}$, and OER and HER performances with low potentials of 388 and $202 \mathrm{mV}$ at 10 
$\mathrm{mA} \mathrm{cm}{ }^{-2}$, respectively, which overperforms Co sample. The electrochemical properties of $\mathrm{Co} / \mathrm{C}$ catalyst indicate the feasibility of the proposed convenient strategy for large-scale preparing $\mathrm{Co} / \mathrm{C}$ trifunctional electrocatalyst. Compared with the Co $2 p$ spectrum of Co sample, that $\mathrm{Co} / \mathrm{C}$ sample displays a weaker peak of metallic cobalt. As a result, more $\mathrm{Co}^{2+/ 3+}$ active species are generated in the $\mathrm{Co} / \mathrm{C}$ sample accompanied by the introduction of carbon particles, which explains the higher activities of $\mathrm{Co} / \mathrm{C}$ than the Co sample. In conclusion, the proposed strategy provides a feasible and convenient method for large-scale synthesizing trifunctional carbides-based catalysts used for energy storage and conversion.

\section{Acknowledgements}

This work was supported by the Foundation of Higher Education of Guangdong Province (No. 2018KZDXM031), and the Guangdong Provincial Key Laboratory of Plant Resources Biorefinery (No. 2021B1212040011).

\section{Supporting Information}

Supporting information for this article is available on the WWW under www.genchemistry.org/EN/10.21127/yaoyigc202 10013.

\section{Conflict of Interest}

The authors declare no conflict of interest.

Copyright (c) 2021 Zihao Zhou, Kangdi Lin, Chenting Peng, Hongyun Huang, Yanli Wu, and Ming Sun. This article is an open access article distributed under the terms and conditions of the Creative Commons Attribution (CC BY) license (http://creativecommons.org/licenses/by/ 4.0/). The use, distribution or reproduction in other forums is permitted, provided the original author(s) or licensor are credited and that the original publication in this journal is cited, in accordance with accepted academic practice. No use, distribution or reproduction is permitted which does not comply with these terms.

\section{References}

[1] Mathur, A.; Halder, A. One-step synthesis of bifunctional iron-doped manganese oxide nanorods for rechargeable zinc-air batteries. Catal. Sci. Technol. 2019, 9, 1245-1254.

[2] Feng, X.; Jiao, Q.; Chen, W.; Dang, Y.; Dai, Z.; Suib, S. L.; Zhang, J.; Zhao, Y.; Li, H.; Feng, C. Cactus-like $\mathrm{NiCo}_{2} \mathrm{~S}_{4} @ \mathrm{NiFe} L D H$ hollow spheres as an effective oxygen bifunctional electrocatalyst in alkaline solution. Appl. Catal. B 2021, 286, 119869.

[3] Tang, Y. J.; Zheng, S.; Cao, S.; Xue, H.; Pang, H. Advances in the application of manganese dioxide and its composites as electrocatalysts for the oxygen evolution reaction. J. Mater. Chem. A 2020, 8, 18492-18514.

[4] Kannari, N.; Ozaki, J.-i. Formation of uniformly and finely dispersed nanoshells by carbonization of cobalt-coordinated oxine-formaldehyde resin and their electrochemical oxygen reduction activity, Carbon 2012, 50, 2941-2952.

[5] Qiu, Y.; Hu, Z.; Li, H.; Ren, Q.; Chen, Y.; Hu, S. Hybrid electrocatalyst $\mathrm{Ag} / \mathrm{Co} / \mathrm{C}$ via flash joule heating for oxygen reduction reaction in alkaline media. Chem. Eng. J. 2021, 132769.

[6] Logeshwaran, N.; Ramakrishnan, S.; Chandrasekaran, S. S.; Vinothkannan, M.; Kim, A. R.; Sengodan, S.; Velusamy, D. B.; Varadhan, P.; He, J.-H.; Yoo, D. J. An efficient and durable trifunctional electrocatalyst for zinc-air batteries driven overall water splitting. Appl. Catal. B 2021, 297, 120405.

[7] Kumar, R. S.; Govindan, K.; Ramakrishnan, S.; Kim, A. R.; Kim, J.-S.; Yoo, D. J. $\mathrm{Fe}_{3} \mathrm{O}_{4}$ nanorods decorated on polypyrrole/reduced graphene oxide for electrochemical detection of dopamine and photocatalytic degradation of acetaminophen. Appl. Surf. Sci. 2021,
556,149765

[8] Ramakrishnan, S.; Velusamy, D. B.; Sengodan, S.; Nagaraju, G.; Kim, D. H.; Kim, A. R.; Yoo, D. J. Rational design of multifunctional electrocatalyst: An approach towards efficient overall water splitting and rechargeable flexible solid-state zinc-air battery. Appl. Catal. B 2022, 300, 120752.

[9] Kannan, R.; Kim, A. R.; Yoo, D. J. Enhanced electrooxidation of methanol, ethylene glycol, glycerol, and xylitol over a polypyrrole/ manganese oxyhydroxide/palladium nanocomposite electrode. $\mathrm{J}$. Appl. Electrochem. 2014, 44, 893-902.

[10] Rasaki, S. A.; Shen, H.; Thomas, T.; Yang, M. Solid-solid separation approach for preparation of carbon-supported cobalt carbide nanoparticle catalysts for oxygen reduction, ACS Appl. Nano Mater. 2019, 2, 3662-3670.

[11] Wu, Y.; Xiao, Z.; Jin, Z.; Li, X.; Chen, Y. The cobalt carbide/bimetallic CoFe phosphide dispersed on carbon nanospheres as advanced bifunctional electrocatalysts for the ORR, OER, and rechargeable $\mathrm{Zn}$-air batteries. J. Colloid Interface Sci. 2021, 590, 321-329.

[12] Zhang, J.; Chen, J.; Jiang, Y.; Zhou, F.; Wang, G.; Wang, R. Tungsten carbide encapsulated in nitrogen-doped carbon with iron/cobalt carbides electrocatalyst for oxygen reduction reaction. Appl. Surf. Sci. 2016, 389, 157-164.

[13] Raziq, F.; Humayun, M.; Ali, A.; Wang, T.; Khan, A.; Fu, Q.; Luo, W.; Zeng, H.; Zheng, Z.; Khan, B.; Shen, H.; Zu, X.; Li, S.; Qiao, L. Synthesis of $S$-Doped porous $g-\mathrm{C}_{3} \mathrm{~N}_{4}$ by using ionic liquids and subsequently coupled with $\mathrm{Au}-\mathrm{TiO}_{2}$ for exceptional cocatalyst-free visible-light catalytic activities. Appl. Catal. B 2018, 237, 1082-1090.

[14] Raziq, F.; Hayat, A.; Humayun, M.; Baburao Mane, S.K.; Faheem, M.B.; Ali, A.; Zhao, Y.; Han, S.; Cai, C.; Li, W.; Qi, D.-C.; Yi, J.; Yu, X.; Breese, M.B.H.; Hassan, F.; Ali, F.; Mavlonov, A.; Dhanabalan, K.; Xiang, X.; Zu, X.; Li, S.; Qiao, L. Photocatalytic solar fuel production and environmental remediation through experimental and DFT based research on CdSe-QDs-coupled P-doped-g- $\mathrm{C}_{3} \mathrm{~N}_{4}$ composites. Appl. Catal. B 2020, 270, 118867.

[15] Reith, L.; Triana, C.A.; Pazoki, F.; Amiri, M.; Nyman, M.; Patzke, G.R. Unraveling nanoscale cobalt oxide catalysts for the oxygen evolution reaction: maximum performance, minimum effort. J. Am. Chem. Soc. 2021, 143, 15022-15038.

[16] Chen, G.; Sunarso, J.; Zhu, Y.; Yu, J.; Zhong, Y.; Zhou, W.; Shao, Z. Highly active carbon/a- $\mathrm{MnO}_{2}$ hybrid oxygen reduction reaction electrocatalysts. ChemElectroChem 2016, 3, 1760-1767.

[17] Qian, C.; Guo, X.; Zhang, W.; Yang, H.; Qian, Y.; Xu, F.; Qian, S.; $\mathrm{Lin}, \mathrm{S}$.; Fan, T. $\mathrm{Co}_{3} \mathrm{O}_{4}$ nanoparticles on porous bio-carbon substrate as catalyst for oxygen reduction reaction. Microporous Mesoporous Mater. 2019, 277, 45-51.

[18] Hyman, M. P.; Vohs, J. M. Reaction of ethanol on oxidized and metallic cobalt surfaces. Surf. Sci. 2011, 605, 383-389.

[19] Xie, P.; Liu, Y.; Feng, M.; Niu, M.; Liu, C.; Wu, N.; Sui, K.; Patil, R. R.; Pan, D.; Guo, Z.; Fan, R., Hierarchically porous Co/C nanocomposites for ultralight high-performance microwave absorption. Adv. Compos. Hybrid Mater. 2021, 4, 173-185.

[20] Li, Z.; Han, X.; Ma, Y.; Liu, D.; Wang, Y.; Xu, P.; Li, C.; Du, Y., MOFs-Derived Hollow $\mathrm{Co} / \mathrm{C}$ Microspheres with Enhanced Microwave Absorption Performance. ACS Sustain. Chem. Eng. 2018, 6, 8904-8913.

[21] Jiang, Z.-L.; Xu, G.-L.; Yu, Z.; Zhou, T.-H.; Shi, W.-K.; Luo, C.-S.; Zhou, H.-J.; Chen, L.-B.; Sheng, W.-J.; Zhou, M.; Cheng, L.; Assary, R. S.; Sun, S.-G.; Amine, K.; Sun, H. High rate and long cycle life in $\mathrm{Li}-\mathrm{O}_{2}$ batteries with highly efficient catalytic cathode configured with $\mathrm{Co}_{3} \mathrm{O}_{4}$ nanoflower. Nano Energy 2019, 64, 103896.

[22] Tang, W.; Chen, D. Mechanism of thermal decomposition of cobalt acetate tetrahydrate. Chem. Pap. 2007, 61, 329-332.

[23] Cao, T.; Wang, D.; Zhang, J.; Cao, C.; Li, Y. Bamboo-like nitrogen-doped carbon nanotubes with Co nanoparticles 
encapsulated at the tips: uniform and large-scale synthesis and high-performance electrocatalysts for oxygen reduction. Chemistry 2015, 21, 14022-14029.

[24] Wang, H.; Zhang, X.; Yin, F.; Chu, W.; Chen, B. Coordinately unsaturated metal-organic framework as an unpyrolyzed bifunctional electrocatalyst for oxygen reduction and evolution reactions. J. Mater. Chem. A 2020, 8, 22111-22123.

[25] Dupont, M.; Hollenkamp, A. F.; Donne, S. W. Electrochemically active surface area effects on the performance of manganese dioxide for electrochemical capacitor applications. Electrochim. Acta 2013, 104, 140-147.
[26] McCrory, C. C.; Jung, S.; Peters, J. C.; Jaramillo, T. F. Benchmarking heterogeneous electrocatalysts for the oxygen evolution reaction. J. Am. Chem. Soc. 2013, 135, 16977-16987.

[27] Li, X.; Dong, F.; Xu, N.; Zhang, T.; Li, K.; Qiao, J. $\mathrm{Co}_{3} \mathrm{O}_{4} / \mathrm{MnO}_{2} /$ hierarchically porous carbon as superior bifunctional electrodes for liquid and all-solid-state rechargeable Zinc-Air Batteries. ACS Appl. Mater. Interfaces 2018, 10, 15591-15601.

Received October 12, 2021

Accepted December 9, 2021 